\title{
Ultrasonografía \\ Embarazo Gemelar del Primer Trimestre
}

\author{
Dr. Guido Parra A.M.D.* Dr. Isarael Díaz R.M.D.* *
}

XIV CONGRESO COLOMBIANO DE OBSTETRICIA Y GINECOLOGIA

Cartagena, Nov. 30 - Dic. 5 de 1981

\section{ULTRASONOGRAFIA}

EMBARAZO GEMELAR DEL PRIMER TRIMESTRE (Huevo embrionadohuevo anembrionado).

\section{INTRODUCCION}

El diagnóstico ultrasonográfico del embarazo intrauterino se realiza en su etapa más temprana a las $4-5$ semanas de edad menstrual, la identificación del polo fetal a las 5 - 6 semanas $(1,2)$, la confirmación de la vitalidad embrionaria (observación de la actividad cardíaca) de las 7.1/2 semanas en adelante (3). Dentro de la patología del primer trimestre de embarazo, el sangrado vaginal constituye una de las complicaciones

- Ginecólogo y Obs. Médico Ultrasonografista del Hospital Universitario de Barranquilla.

* Ginecólogo y Obs. Director Científico de la Clínica La Asunción. más frecuentes y su remisión para examen ultrasonográfico una de las más asiduas, con el objeto de esclarecer diagnóstico y comprobar la vitalidad embrionaria.

A la unidad de ultrasonidos, de la Clínica Asunción de la ciudad de Barranquilla, fueron remitidas 125 pacientes con este diagnóstico clínico (sangrado genital del primer trimestre $\mathrm{y} / \mathrm{o}$ amenaza de aborto), en el transcurso de un año (agosto 1980-81); seis de ellas $(4.8 \%$ ) presentaron la primer examen ultrasonográfico características de embarazo gemelar y se delimitaron dos sacos gestacionales; en uno se identificó polo ó botón embrionado con movimientos cardíacos (dependiendo esto último de la edad gestacional de la paciente) y en el otro se identificó polo embrionario (huevo huero ó anembrionado). Todas las pacientes fueron remitidas por especialistas en Ginecología y Obstetricia.

La distribución de los exámenes ultrasonográficos, datos de la historia clínica, características de su evolución y tratamiento se encuentran en el Cuadro No. 1 
Cuadro No. 1

\begin{tabular}{|c|c|c|c|c|c|c|}
\hline CASOS & EDAD & PARIDAD & $\begin{array}{l}\text { SINTOMA- } \\
\text { TOLOGIA }\end{array}$ & EXAMEN U.S. INICIAL & TRATAMIENTO & EVOLUCION \\
\hline 10. & 30 & $G_{2} P_{1} A_{0}$ & $\begin{array}{l}\text { Sangrado } \\
\text { Vaginal } \\
\text { Indoloro }\end{array}$ & $\begin{array}{l}\text { 6o. dia de Sangrado } \\
10 \text { semanas de Ges- } \\
\text { tación.- }\end{array}$ & Reposo absoluto & $\begin{array}{l}\text { Satisfactoria } \\
\text { Parto prematuro en } \\
\text { área rural a la } 36 \\
\text { semana.- }\end{array}$ \\
\hline 2o. & 22 & $G_{1} P_{0} A_{0}$ & $\begin{array}{l}\text { Sangrado } \\
\text { Vaginal } \\
\text { Indoloro }\end{array}$ & $\begin{array}{l}\text { 1er. día de Sangrado } \\
8 \text { semanas de Gesta- } \\
\text { ción.- }\end{array}$ & $\begin{array}{l}\text { Reposo absoluto } \\
\text { Antieméticos }\end{array}$ & $\begin{array}{c}\text { Parto vaginal } \\
\text { Embarazo a término }\end{array}$ \\
\hline 3o. & 34 & $\mathrm{G}_{4} \mathrm{P}_{2} \mathrm{~A}_{1}$ & $\begin{array}{l}\text { Sangrado } \\
\text { Vaginal } \\
\text { Indoloro }\end{array}$ & $\begin{array}{l}\text { 20. día de Sangrado } \\
8 \text { semanas de Gesta. } \\
\text { ción.- }\end{array}$ & $\begin{array}{l}\text { Reposo absoluto du- } \\
\text { rante } 15 \text { días, igual } \\
\text { tratamiento a la se- } \\
\text { mana No. } 20 \text {.- }\end{array}$ & $\begin{array}{l}\text { Actualmente en el 8o. mes- } \\
\text { Evolución satisfactoria.- }\end{array}$ \\
\hline 40 & 20 & $G_{1} P_{0} A_{0}$ & $\begin{array}{l}\text { Sangrado } \\
\text { Vaginal } \\
\text { Indoloro }\end{array}$ & $\begin{array}{l}\text { 1er dia de sangrado } \\
7 \text { semanas de Ges. } \\
\text { tación. - }\end{array}$ & Reposo Absoluto & $\begin{array}{c}\text { Parto vaginal } \\
\text { Embarazo a término. }\end{array}$ \\
\hline 50 & 25 & $G_{2} P_{0} A_{0}$ & $\begin{array}{l}\text { Sangrado } \\
\text { Vaginal } \\
\text { Indoloro }\end{array}$ & $\begin{array}{l}1 \text { er dia de Sangrado } \\
12 \text { semanas de Ges. } \\
\text { tación }\end{array}$ & Reposo Absoluto & $\begin{array}{c}\text { Parto Vaginal } \\
\text { Embarazo a término }\end{array}$ \\
\hline 60 & 18 & $G_{1} P_{0} A_{0}$ & $\begin{array}{l}\text { Sangrado } \\
\text { Vaginal } \\
\text { Indoloro }\end{array}$ & $\begin{array}{l}\text { 1er dia de Sangrado } \\
6 \text { semanas de Ges } \\
\text { tación. - }\end{array}$ & Reposo Absoluto & $\begin{array}{l}\text { Actualmente en el } \\
\text { 6o. mes.-- Evolución } \\
\text { satisfactoria.- }\end{array}$ \\
\hline
\end{tabular}

U.S. Uitrasonoyrafico -

\section{Material y Métodos}

Todas las pacientes fueron examinadas por el mismo médico ultrasonografista y los hallazgos fueron imprimidos en películas Polaroid Tipc 667, tomando al menos cuatro fotografías por cada caso (las más representativas); el ecógrafo utilizado fue de imágen dinámica con un traductor de arreglo lineal de 3,5 Mghz, con una resolución axial de $2=4 \mathrm{~mm}\left({ }^{*}\right)$.

Los exámenes ultrasonográficos fueron realizados con la vejiga llena y vacía efectuándose, cortes longitudinales y transversales identificando el útero y su contenido, al igual que los anexos, reportando los hallazgos de manera tra-

$\left(^{*}\right)$ Ecografo ADR (Advance development research), modelo 2130. Tempe. Arizona. dicional; las pacientes fueron alentadas para continuar asistiendo (semanalmente al principio y mensualmente después del primer trimestre) a la unidad de ultrasonidos, explicándoles los hallazgos y conclusiones de otros observadores sobre estos casos.

\section{Resultados}

Las 6 pacientes presentaron imágenes bien definidas de dos sacos intrauterinos, con aparente buena reacción decidual y con diferencias notables en sus diámetros, favoreciendo al saco embrionado (sólo en uno de ellos los diámetros fueron iguales para ambos sacos), presentándose en los exámenes siguientes disminución paulatina de la imágen anembrionada, hasta su total desaparición alrededor de las semanas 14-18 de la gestación; la persistencia de la imágen 
sólo se observó en el caso No. 3 del Cuadro No. 1, en donde persistió hasta la semana 28 de la gestación.

Las características generales observadas en el saco gestacional anembrionado fueron las siguientes:

a. Su contorno fue bien definido, separándose claramente del otro saco gestacional.

b. El líquido observado en su interior fue de densidad ecogénica baja y sin ecos que sugirieran la presencia de polo embrionario.

c. Su tamaño fue en general siempre menor que el observado para el saco embrionado.

d. El seguimiento de éste saco gestacional demostró disminución progresiva de sus diámetros (absorción de su contenido) y redundancia de su contorno (decidua ó continente),

e. Desaparición de la doble imágen observada en las inicias del segundo trimestre.
Ninguna de las pacientes observadas con éstas características, y basados en conclusiones anteriormente publicadas, recibió medicación para su amenaza de aborto, instituyéndose como único tratamiento reposo físico, psíquico y sexual, en 4 de ellas desaparecieron los síntomas del sangrado vaginal a la semana de instaurado el reposo, en una a las dos semanas y sólo una de ellas presentó nuevamente sangrado vaginal a la semana 20 del embarazo (la misma paciente en la cual persistió la imágen del segundo saco gestacional hasta la semana 28) Figura No. 7.

Los embarazos continuaron evolucionando sin complicaciones y en los siguientes exámenes ultrasonográficos se observó un sólo feto sin anomalías aparentes, todos con placenta de implantación alta; en la actualidad 4 de ellas han dado a luz productos sanos cuyo peso al nacer se encontró por encima de los 2500 grms (inclusive el caso No. 1), los 2 embarazos restantes continuán sin complicaciones $y$ actualmente se encuentran en el tercer trimestre. La edad de las pacientes varió entre los 18 y los 34
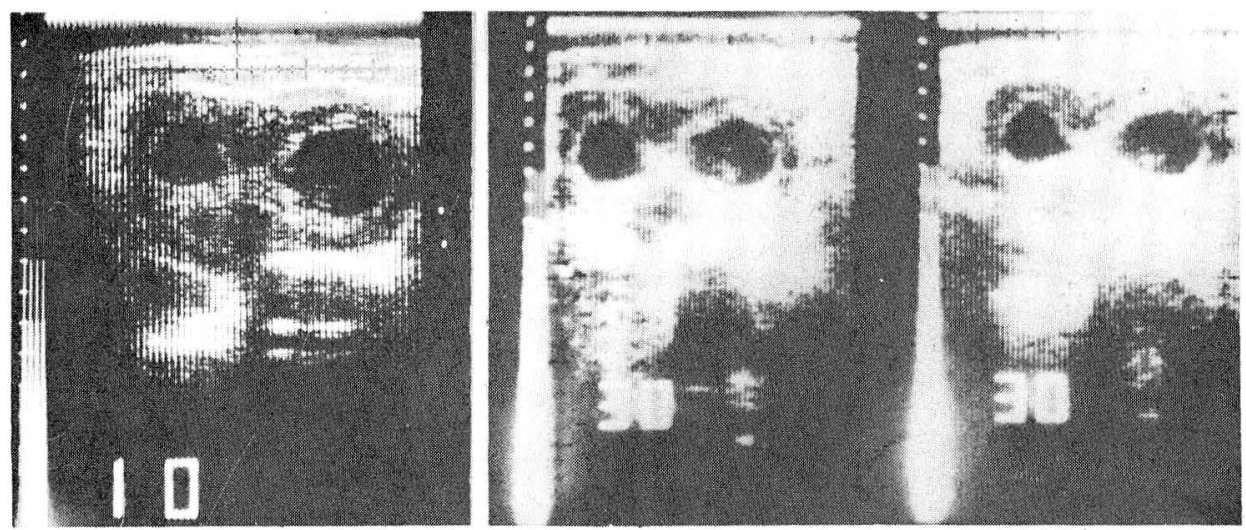

Fig. No. 1: Caso No. 3 8a. y 9a. semanas de gestación, observándose 2 sacos gestacionales: embrionado el de la izquierda (imágen especular), y sin ecos en su interior el derecho. 

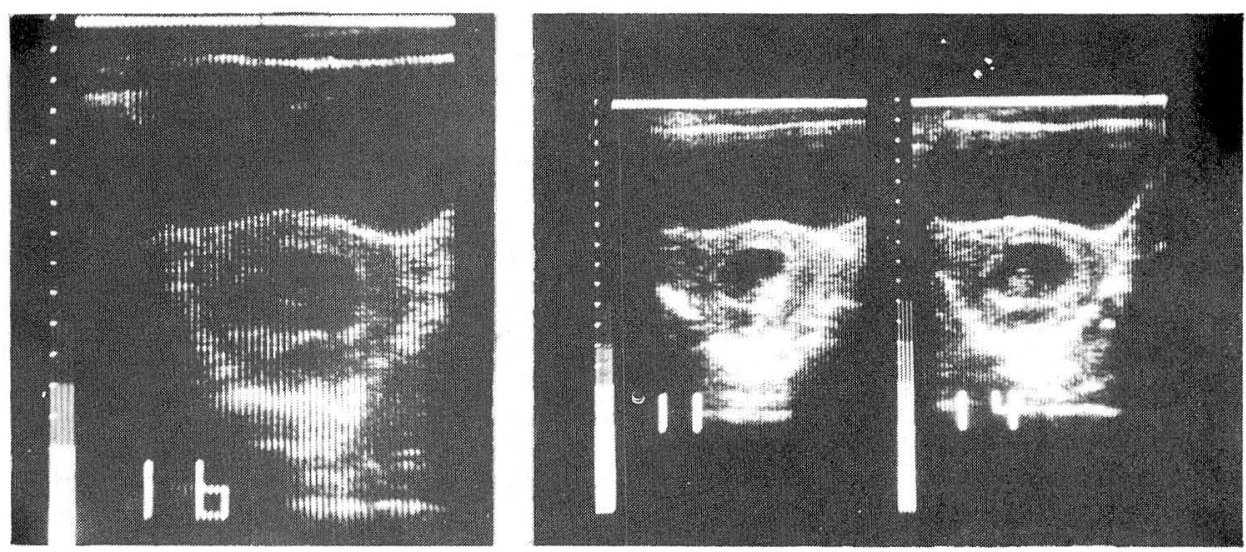

Fig. No. 2: Caso No. 2 a la 8a. semana: el saco anembrionado muestra ya su tamaño menor que el saco saludable con embrión en su interior.

años, dos de ellas tenían antecedentes de gemelares en la familia y una de ellas habia presentado amenaza de aborto en los 3 embarazos precedentes, terminando uno de ellos en aborto del primer trimestre (Caso No. 3); tres de las pacientes eran primíparas, dos secundíparas y una multípara. Figura 1 y 2.

\section{Discusión y comentarios.}

La presencia de gestación con huevo anembrionado ha sido planteada desde los trabajos de HERTIG y SHELDON en 1943 (4), demostrándose la normalidad del desarrollo de las vellosidades coriales (5) en ellos, al igual que la normal producción de gonadotrofina coriónica hasta la 8-9 semana de gestación, (6) cuando generalmente se instauraba el proceso de expulsión.

La introducción de los ultrasonidos como método no invasivo de diagnóstico intrauterino en el primer trimestre de embarazo y su amplia difusión en los últimos 10 años, ha permitido diagnósticar el huevo huero ó anembrionado incluso antes de las manifestaciones clínicas de aborto, comprobándose también la tendencia a retenerse hasta mediados del tercer mes (7). Otros autores (8), habían reportado casos diagnosticados como embarazos gemelares en el primer trimestre, obteniéndose solo un feto al momento del parto; estos casos fueron puestos en duda, sugiriendo los investigadores la posibilidad de una falsa interpretación de la imágen debido al uso de ecógrafos estáticos solamente, en la exploración ó aduciendo artefactos (saco gestacional en "reloj de arena"), causados por la compresión de la vejiga urinaria distendida sobre el útero y su contenido (9); estas dudas han sido clarificadas por los últimos trabajos que utilizando ecógrafos estáticos y dinámicos han hecho observaciones similares a las nuestras (10).

En el año 1978 FINBERG y BIRNHOLZ (11) presentaron ultrasonográficas de 22 pacientes en donde se observaron imágenes de dos sacos intrauterinos, con embrión en uno de ellos; esta publicación aunada a las observaciones anteriores mostraba un buen pronóstico en la evolución del embarazo hasta su 


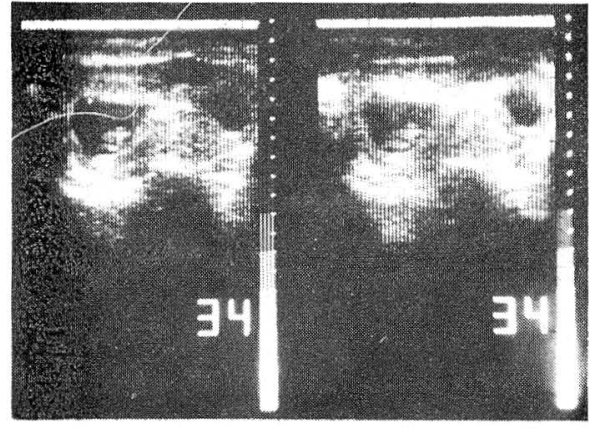

Fig. 3: Se observan los 2 sacos gestacionales intrauterinos cuya evolución mostró desaparición del saco anembrionado antes de las 12 semanas.

término, sirviéndonos de base para las propuestas terapéuticas en nuestros casos.

Sin embargo, pensamos que en ninguno de estos trabajos se presentaron signos ultrasonográficos para establecer con mayor exactitud diagnósticos con otras entidades, que podrian simular igual diagnóstico y aumentar ficticiamente el porcentaje de los mismos, al igual que empobrecer el pronóstico hasta ahora aceptable de evolución de estos embarazos; los posibles diagnósticos a diferenciar se enumeran a continuación:

1. Utero arcuato, que comprimido por la técnica exploratoria de la vejiga llena produzca imágen en reloj de arena del saco gestacional intrauterino (12).

2. Utero bicorne, con saco gestacional embrionado en uno de sus cuernos y formación de seudo saco gestacional en el otro (13) (16), Figura No. 8.

3. Desprendimiento de la decidua o separación de la membrana de la pared uterina, produciéndose así una cavidad intrauterina anembrionada y separada de la cavidad embrionada (imágen descrita como "tienda de campaña"). (14).
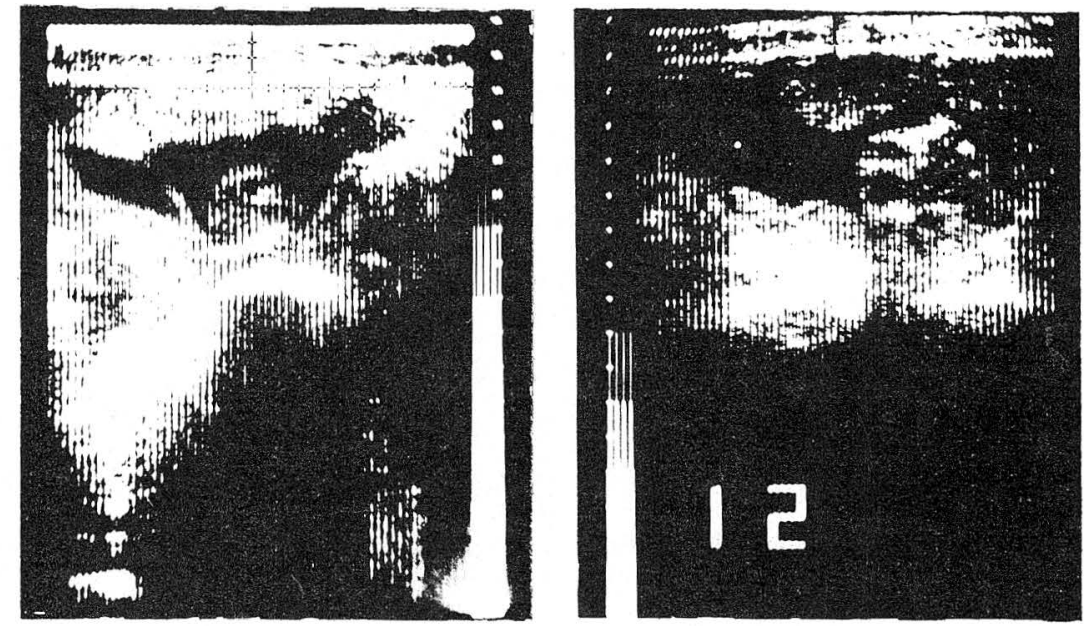

Fig. No. 4: Caso No. 5: detállese que el tabique que divide en 2 cavidades la imágen "a" es más grueso que el de la "b" y sale directamente de la placenta, mientras el de la " $b$ " no tiene relación con ella; ésta corresponde a un saco en tienda de campaña, descritos en las fig. 5 y 6. 


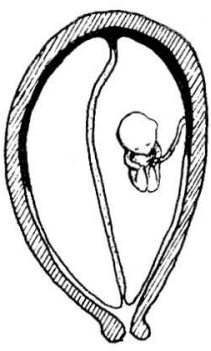

8-9 Semanas

Vibraciones (-)

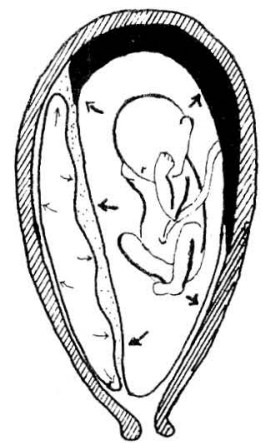

12 ó mós semanas

Vibraciones $(t+)$

Fig 5

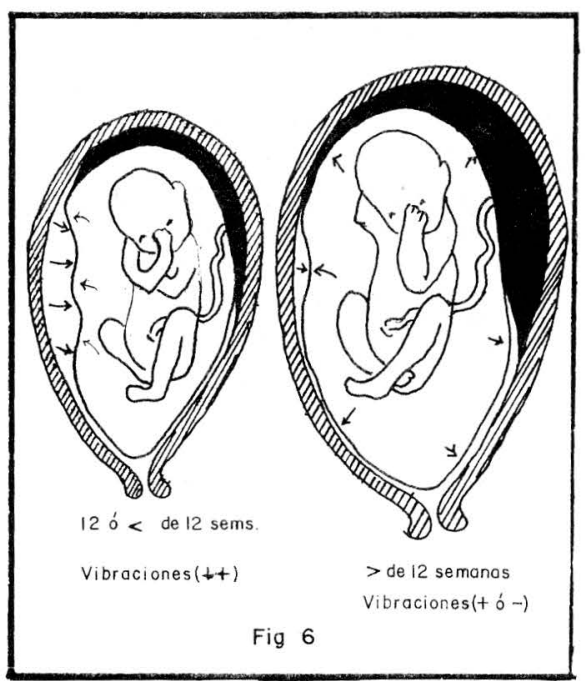

Fig 6

Figuras 5 y 6 muestran la evolución diferente y los signos ultrasonográficos observados para los casos de huevo embrionado - huevo anembrionado y los descritos en el

numeral 4 .

4. Quistes placentarios ó miomas intramurales y submucosos acompañando a la gestación normal con feto único Figura No. 4. La mejor manera de excluir estos diagnósticos la constituye el realizar un concienzudo examen ultrasonográfico aunado al uso de la imágen dinámica, realizando cortes longitudinales y transversales de la región pélvica, al igual que observaciones con la vejiga llena, distendida y vacía, con el objeto de aminorar los artefactos causados por la presión vesical. El seguimiento de la imágen observada es de vital importancia para la diferenciación, especialmente de los numerales 3 y 4, como lo mostramos en las Figuras 5 y 6 , ya que el contenido del saco gestacional anembrionado sufre un proceso de absorción, dejando redundante su continente, produciéndose vibraciones en este último a las maniobras de baloteo externo en los días y semanas subsiguientes al primer examen ultraso-

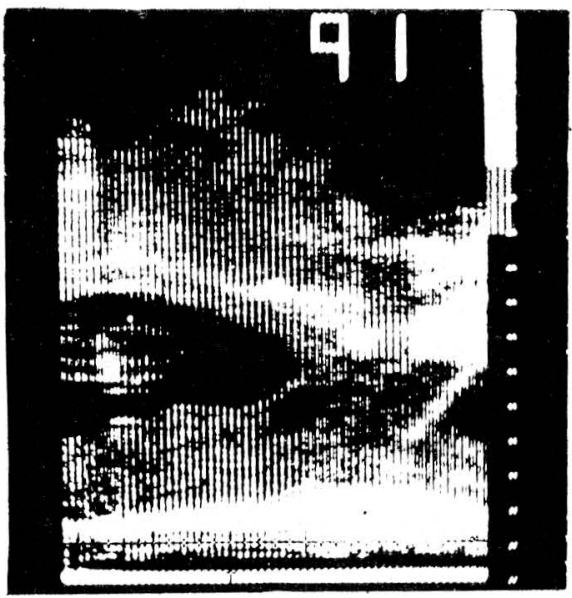

Fig. 7: Imagen que persistió hasta las 28 semanas, caso No. 3, que aparenta ser solo un quiste placentario subcoriónico; por su evolución y los signos ultrasonográficos descritos en las fig. 5 y 6 sabíamos se trataba del saco gestacional vacío en vías de desaparición. 


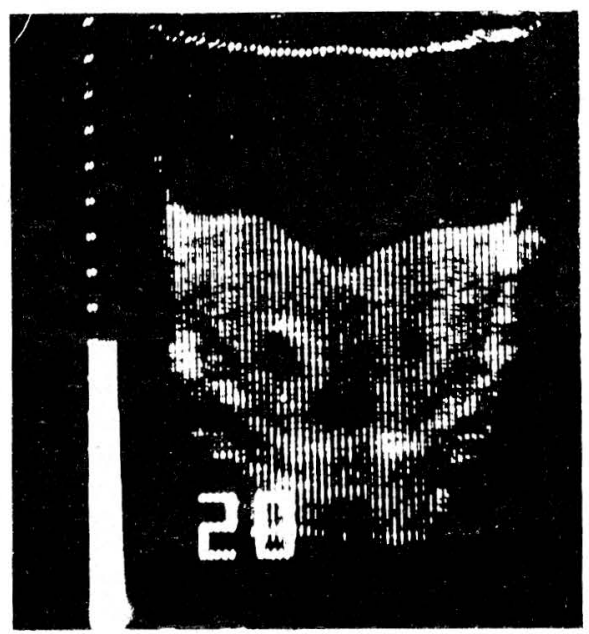

Fig. 8: Caso de útero bicorne con embarazo saludable de 6 semanas en su cuerpo derecho, e imagen de seudo saco gestacional en el iz. quierdo.

nográfico (acentuando cada día más), mientras que en el proceso activo de separación de la membrana amniótica (Numeral No. 4) las vihraciones serían más marcadas en la fase inicial que en la fase terminal de reabsorción del hematoma o del líquido amniótico extravasado, ya que la membrana separada se iría adosando a la pared uterina, estirándose nuevamente a su medida anterior.

Las observaciones anteriormente anotadas nos han servido para seleccionar éstos casos, de aproximadamente 30 que en el examen inicial podrian ser considerados como embarazos gemelares; huevo embrionado - huevo anembrionado.

Entre las posibles hipótesis que expli. carian este hecho, debemos mencionar li al ta frecuencia observada en los abortos espontáneos del huevo anembrionado $(32 \%, 49$ y $67 \%) 4,5$ y seguramente una mayor frecuencia de embarazos gemelares al momento de la fecundación; las otras posibilidades caerían dentro del campo de la superfetación ó superfecundación (15); la primera quedaría suprimida ya que no se ha demostrado embrión en el segundo saco, ni en los partos se ha encontrado un litopedium correspondiente. Consideramos que estudios posteriores sobre el huevo anembrionado como saco gestacional único, cuya frecuencia es mayor, permitirán deducir hipótesis más ajustadas a la realidad del origen y su incidencia en el embarazo gemelar.

Creemos también y estamos haciéndolo con los casos nuevos, que la producción de hormonas gonadotróficas en éstos casos, sea cuantitativamente similar a la producida en los embarazos gemelares normales, ya que la producción de hormonas en el huevo anembrionado ha sido dentro de los rangos normales para un embarazo único (6), por lo menos hasta que se inicia el proceso de reabsorción ó expulsión del mismo; esta simple prueba sumada a los signos ultrasonográficos arriba descritos servirá como pilar para establecer un diagnóstico diferencial con los 4 numerales anteriormente discutidos.

\section{Resumen y Conclusiones}

Presentamos 6 casos de embarazos gemelares con características de huevo embrionado y huevo anembrionado, que reafirman las observaciones ultrasonográficos para establecer un buen diagnóstico diferencial con entidades que pueden producir imágenes similares. La evolución de estos casos confirman el buen pronóstico del embarazo (de ahí la importancia del diagnóstico diferencial), con producción de fetos a término sin alteraciones en su crecimiento y la cesación de la sintomatología del sangrado vaginal con la instauración del reposo absoluto de la paciente como única medida terapéutica. 
En especial queremos recordar la importancia del examen ultrasonográfico en las pacientes con amenaza de aborto del primer trimestre antes de adoptar medidas terapéuticas o de practicar el legrado uterino.

Se describe un nuevo signo ultrasonográfico de seguimiento y aplicación al diagnóstico diferencial de entidades que pueden producir durante el embarazo imágenes ecográficas de 2 sacos gestacionales intrauterinos, presentándose 6 casos de huevo embrionado - huevo anembrionado.

Confirmándose las impresiones de otros autores sobre la importancia del diagnóstico oportuno y el buen pronóstico de estos casos.

\section{ULTRASONOGRAPHY \\ FIRST TRIMESTER DOUBLE PREGNANCY}

\section{Summary and conclusions}

In this article, six cases of double pregnancies are analyzed. In some cases there are anembryonic eggs, as confirmed by ultrasonographic observation, in order to establish an accurate diagnosis regarding other entities which may produce similar images. The evolution of these cases confirms a good prognosis for the gestation; resulting in fetuses with no alterations of growth, and cessation of vaginal bleeding by prescribing absolute inactivity as the only indicated therapeutic measure.

\section{Bibliografía}

1. ABDULLA U. Sonar in very early pregnancy. J. Congreso Mundial de Diagnóstico Ultrasónico en Médicina. Viena, 1969. Ultrasonogr. Med., 3: 185-192, 1969.

2. BONILLA MUSOLES F. y PEREZ GIL $M$. Control con ultrasonidos de la gestación normal y patológica en las 16 primeras semanas. Rev. Esp. Obstet. Ginec. 30: 387-400, 1971.
We want to make special emphasis on the advantages of ultrasonography for patients with a threatened abortion in the first trimester of pregnancy, before considering theraphy and uretrine curettage.

A new ultrasonographic sign is described for follow-up and application of differential diagnosis of entities that may produce during gestation images of two intrauterine gestational eggs, embryonic or anaembryonic. Importance of timely diagnosis and good prognosis, as expressed by other authors is thus confirmed.

3. JOUPPILA P. PIIROINEN O. UItrasonic diagnosis of fetal life in early pregnancy. Obstet Gynecol. 46: 616-620, 1975.

4. HERTIG AT, SHELDON WH. Minimal criteria required to prove prima faciex cause of traumatic abortion or miscarriage. An analysis of 1000 spontaneus abortions. Ann. Sur. 117: 596, 1943.

5. JOUPPILA P., HERVA R.: Study of blighted ovum by ultrasonic and histo- 
pathologic methods. Obstet Gynecol. 55: 574-578, 1980.

6. JOUPPILA P., HUHTNIEMI J. TAPA. NAIEN J.: Early pregnancy failure. A study by ultrasonic and hormonal methods. Obstet Gynecol, 55: 42-46, 1980.

7. ROBINSON HP: The diagnosis of early pregnancy failure by sonar. $\mathrm{Br} \mathrm{J}$. Obstet Gynecol 82: 849, 1975.

8. ROBINSON HP. Caines JS: Sonar evidence of early pregnancy failure in patients with Twin conceptions. $\mathrm{Br}$ J. Obstet. Gynecol 84: 22-25, 1977.

9. BONILLA MUSOLES F., y PEREZ GIL M.: Diagnóstico con ultrasonidos en Obstetricia y Ginecología, Barcelona, Editorial Científico Médica. 180-181. 1977.

10. SHARMA S: Ultrasound Diagnosis of rare abnormalities in twin pregnancies. White DN, Brown RE, eds: Ultrasound in medicine. New York, Plenum Press, Vol. 3A. 743-744, 1977.
11. FINBERG JH, BIRNHOLZ CJ.: UItrasound observations in multiple gestations with first trimester bleeding: The Blighted Twin. Radial, 132: 137-142, 1979.

12. HOBBINS $\mathrm{Cl}$,: :Diagnostic Ultrasound in Obstetries. Clinics in Diagnostic Ultrasound No. 3 Churchill Livinsgtone, New York, Edinburgh y Londres: 13-21, 1979.

13. KOBAYASHI M. HELLMAN L $M \quad y$ FILLISTE LP.: Ultrasound. An aid in the diagnosis of ectopic pregnancy. Amen J. Obstet, Gynec. 103: 1131-1140, 1969.

14. BONILLA MUSOLES F. y PEREZ GIL M.: Ecografía Obstétrica, Ginecológica y mamaria. Barcelona, Edit. JIMS. 461. 1981.

15. GREENHILL J P, Obstetrics. Philadelphia and London. WB Saunders company, 488-499, 1961.

16. SPIRT AB, O'HARA KR y GORDON L.: Pseudogestacional sac in ectopic pregnancy: Sonographic and pathologic correlation. J. Clin. Ultrasound. 9: 338340, 1981. 